\title{
Dyeing effect on silk-fabric with vegetable dye using green- coconut (cocos nucifera) shell
}

\author{
Ayesha Akhter ${ }^{1}$, Md. Kobad Hossain ${ }^{2}$, Mrs. Seatara Khatun ${ }^{3}$, M.A. Rabbi ${ }^{4}$ and \\ Most Halima Khatun ${ }^{5}$ \\ 1, 2,3,4,5 BCSIR Laboratories, Bindodpur Bazar, Rajshahi-6206.
}

\begin{abstract}
Silk fabric was dyed with vegetable dye using green coconut shell extract. The dyeing characteristics of the dye were investigated with regard to dye concentration, $p H$ of dye-bath, different mordant uses and dyeing time. A small variation in these above experimental parameters gave numerous shades of satisfactory fastness when applying various destructive agents like wash and light. In all cases the optimum dyeing time was one hour and the $\mathrm{pH}$ of dye bath was 4.0-4.5 for 2-3\% dye concentration and 3.0-3.5 for 5\% dye concentration.

Keywords: Aluminum sulphate; Dye concentration; Dyeing time; Green coconut shell, Poly phenol, Mordant; pH; Stannous chloride.
\end{abstract}

\section{Introduction}

Natural dyes are obtained from roots, leaves, barks, fruits and fruit-coat or wood of the plants ${ }^{1}$. It exhibits better bio-degradability and has a better suitability with the environment and its use in coloration of fabric materials is the consequences of increased environmental awareness. Natural dyes also possess lower toxicity and allergic reaction then synthetic dyes ${ }^{2}$. Generally natural dyes are used in food-stuffs for safety but most of them are used in craft dyeing. Indigo, a blue natural dye, originally obtained from natural, materials, turmeric, a yellow natural dye, was extracted from the root of the turmeric or Indian saffron plants, catechu, a brown dye obtained from the acacia catechu plant stem.

Green coconut (cocos nucifera), locally called 'dab' grows abundantly in Bangladesh, especially in coastal region. Its water is used for refreshing and diorheal diseases and the shell is merely wasted in this country. The whole or every part of this tree is claimed as a dye-ware, especially the husk enclosing the fruits ${ }^{4}$. Phenol constituent was obtained by destructive distillation of coconut shell at $280^{\circ} \mathrm{C}^{5}$. Coloring materials have been prepared from the extract of coconut-shell by coupling with some diazotized compounds. A reddish brown dye was obtained from the coconut-shell with the coupling of diazotized $4-\mathrm{H}_{2} \mathrm{NC}_{6} \mathrm{H}_{4} \mathrm{SO}_{3} \mathrm{Na}$ which is useful as a wood stain ${ }^{6}$. The aqueous extract of green coconut-shell contains huge amount of polyphenolic materials which acts as coloring or dyeing materials.

In this paper, we have dealt extensively the details of dyeing of silk fabrics with this natural coloring matter in the presence of a mordant. The dependence of color and shade on different experimental parameters i.e., dye concentration, $\mathrm{pH}$ of the dye bath, dyeing period as well as the action of different destructive agents e.g., light and wash on the dyed sample have been studied.

\subsection{Extraction and Preparation of dye}

\section{Materials and Methods}

Green coconut shells were collected from local market. After washing to free from dirt, the shell was cut into pieces and smashed in wooden mortar and squeezed to get extract. The extract was then filtered with cloth and paper and then concentrated by boiling to get paste like mass. This concentrated mass was used as green coconut-shell based vegetable dye.

\subsection{Identification of the phenolic compounds}

The presence of phenolic compounds in green coconut shell extract was examined by ferric chloride test. $1 \mathrm{ml}$ of juice was mixed with $1 \mathrm{ml}$. ethyl alcohol and $1 \mathrm{ml}$. $1 \mathrm{~N}$ hydrochloric acid. Then 1 drop of $3 \%$ ferric chloride solution was added to this solution. A deep red coloration indicated the presence of phenolic compounds in the juice.

\subsection{Specification and size of the fabric}

The silk fabrics used for dyeing in the present work were collected from sericulture Industry, Rajshahi. Fabrics of size measuring $25 \mathrm{~cm} \times 30 \mathrm{~cm}$ were used for dyeing tests and half portion of each of the sample was used for light and washing tests. 


\subsection{Degumming of silk fabric}

The fabric to be dyed was dipped in a 3\% soap solution and heated to boiling for 1 hour in order for degumming and then washed thoroughly 2-3 times with distilled water.

\subsection{Dyeing of silk fabric}

The dyeing experiments were carried out in two steps e.g., mordanting and then dyeing.

2.5.1 Mordanting: Silk fabric was treated with an aqueous solution containing $2 \%$ stannous chloride, $1 \%$ sodium potassium tartrate or cream of tartar and oxalic acid at $90^{\circ} \pm 5^{\circ} \mathrm{C}$ for 20 minutes. Fixation of the mordant on the fabric was carried out with trisodium phosphate at $90^{\circ} \pm 5^{\circ} \mathrm{C}$ for another 20 minutes. Here mordant was acted as a key or bridge between the dye and the fibre ${ }^{7}$. The mordanted fabric was then taken out of the bath, squeeze and dried at room temperature.

2.5.2 Dyeing: Dye-bath was prepared by dissolving green coconut-shell based vegetable dye (dye content 2$5 \%$ ) containing phosphoric acid as the buffering agent (pH range from 3.0-5.0). The mordanted fabric was then dipped in dye bath and heated at $90^{\circ} \pm 5^{\circ} \mathrm{C}$ for 1 hour. (In all cases of mordanting and dyeing the liquor to material ratio was maintained at 20:1). The dyed fabric was then taken out of the bath, rinsed first with water and then thoroughly washed with soap and water and dried in air. The results are collated in table II and III. The same mordanting and dyeing procedure was followed for $2 \%$ aluminium sulphate.

In case of unmordauted fabric only dyeing procedure had been followed and the results were given in Table-I.

\subsection{Fastness Properties}

2.6.1 Light fastness: The dyed samples were exposed to sunlight for 8 hours a day for fifteen consecutive days. Any changes of shades were measured with the help of Grey scale. The results are shown in table I, II and III.

2.6.2 Wash fastness: The dyed samples were washed with $3 \%$ soap solution for 20 minutes, squeezed, dried and allowed to dry at defused sunlight. The dried samples were compared with the controlled sample by means of Grey scale. The results are shown in table I, II and III.

\section{Results and Discussion}

The experimental results showed that silk-fabric can be dyed with vegetable dye using green coconut shell when a mordant is used. It is obvious that the color of the dyed sample depends on the mordant used as shown in table II and III. The results obtained relating to color and corresponding fastness to light and washing when green coconut-shell based dye was applied to unmordanted and mordanted (stannous chloride and aluminium sulphate) silk fabric under different $\mathrm{pH}$ condition, dye concentration and dyeing time are presented in table I, II and III respectively.

It is observed that in the application of green coconut-shell based dye to unmordanted and mordanted silk fabric the tone of dyeing was appreciably influenced by the $\mathrm{pH}$ of the dye bath, the concentration of dye and also dyeing period.

In case of unmordanted fabric, the tone obtained on the material was very pale brown yellow when dyeing were carried out with $2 \%$ dye buffered at $\mathrm{pH} 3.0-4.0$, while $\mathrm{pH}$ above 4.0 the tone of dyeings changed to pale brown yellow.

The use of stannous chloride as mordant affords brown yellow color, and fawn for aluminum sulphate. In all cases shades of heavier tone i.e, light to medium to deep have been obtained when higher percentage of the vegetable dye is used. Moreover with the same amount of the vegetable dye used, the shades became heavier as the dyeing period was increased. But once the dyeing time is saturated, no further deepening of the shade is achieved.

Also the tone of dyeing in case of unmordanted and mordanted silk fabric was appreciably influenced by the $\mathrm{pH}$ of the dyeing bath. The shades are changed from light to medium to deep at $\mathrm{pH}$ ranged from 3.0-3.5 to 3.5-4.0 to 4.0-4.5 respectively. $\mathrm{pH}$ above 4.5 the shades are almost the same as 4.0-4.5. The optimum $\mathrm{pH}$ of the dye bath in case of two mordanted fabric is 4.0-4.5 for $2 \%$ and $3 \%$ dye concentration. At 5\% dye concentration deep shades are obtained at $\mathrm{pH} 3.0-3.5$. But the optimum dyeing time is almost equal (1 hour) in all cases.

The shade is influenced by $\mathrm{pH}$ of the bath. Probably it is due to the different in the extent of protonation of amino acid to ammonium $\left(-\mathrm{NH}_{3}{ }^{+}\right)$ion of silk fabric and subsequent combination between negatively charged hydroxyl groups $\left(\mathrm{OH}^{-}\right)$present in the polyphenolic compounds of green coconut-shell based dye molecule.

$\mathrm{H}_{2} \mathrm{~N}-\left(\mathrm{R}_{1}-\mathrm{NH}-\mathrm{CO}-\mathrm{R}_{2}\right)_{\mathrm{n}}-\mathrm{COOH}+\mathrm{H}^{+} \rightarrow{ }^{+} \mathrm{NH}_{3}-\left(\mathrm{R}_{1}-\mathrm{NH}-\mathrm{CO}-\mathrm{R}_{2}\right) \mathrm{n}-\mathrm{COOH}$

Dye-OH $+{ }^{+} \mathrm{NH}_{3}-\left(\mathrm{R}_{1}-\mathrm{NH}-\mathrm{CO}-\mathrm{R}_{2}\right)_{\mathrm{n}}-\mathrm{COOH} \rightarrow$ Dye-O-NH $\mathrm{N}_{3}-\left(\mathrm{R}_{1}-\mathrm{NH}-\mathrm{CO}-\mathrm{R}_{2}\right) \mathrm{n}-\mathrm{COOH}+\mathrm{H}^{+}$. 


\section{Conclusion}

Dyeing of silk fabric having appreciable depth of color and good fastness (light and wash) properties is achieved with vegetable dye using green coconut-shell when a mordant is used at suitable $\mathrm{pH}$ of dye solution. In case of unmordanted fabrics the tone of dyeing are more dull and poor and slight fast to light and distinct loss in depth of dyeing on washing with soap. But in case of tin and aluminium mordanted fabric the tone of dyeing increase from light to medium to heavy shades and bearing fair to good fastness properties (light and wash). Thus we can utilize waste green coconut-shell as a cheap source of vegetable dye in silk fabric.

\section{References}

[1] A.F. Hill, Economic Botany, $2^{\text {nd }}$ Edition (Mcgraw-hill publications in the botanical sciences, 1951, p. 225)

[2] M.M. Alam, M.L. Rahman and M.Z. Haque, Bangladesh J. Sci. Ind. Res. 2007, p. 217-222.

[3] V. Kumar and B.V. Bharti, the Indian Textile Journal, 1998, p. 18-20.

[4] George Watt, Dictionary of Economic products of India (International Book Distributors, Dehradun, India, 1972, Vol. 2, p. 426)

[5] Anonymous, The Wealth of India, A Dictionary of Indian Raw Materials and Industrial Products, (New Delhi, Publications and Information Directorate 1950, Vol. 2, p. 278)

[6] Menon, Chathanth, Chaithanya, Preparation of Coloring Materials from coconut-shell derivatives, Indian Patents, $147728,1986$.

[7] S.R. Cockelt and K.H. Hilton, Dyeing of Cellulose fibre, (1961, p. 135)

Table-I

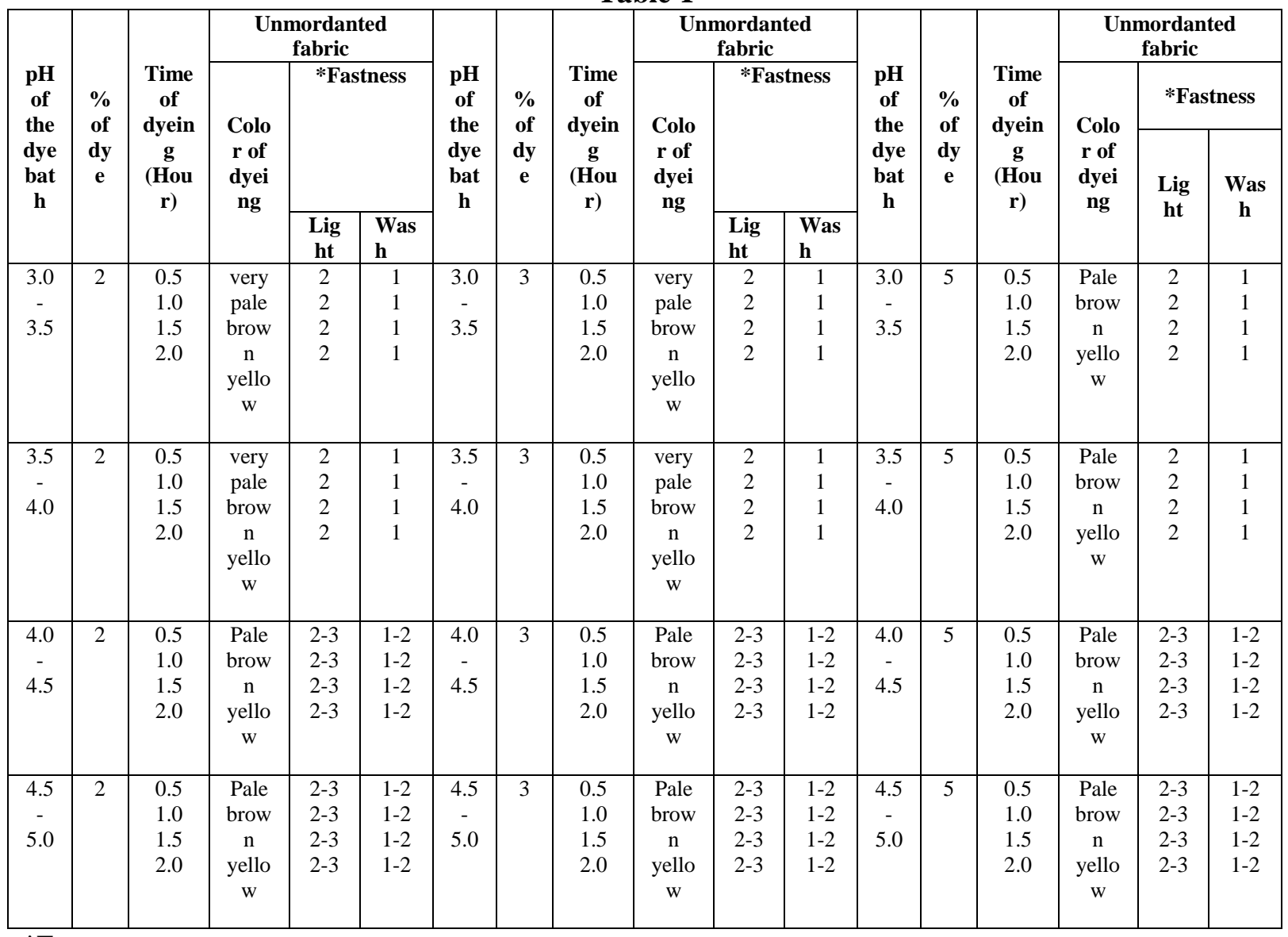

\begin{tabular}{|c|c|c|}
\multicolumn{2}{|c|}{ *Fastness } \\
\hline Grade & Light & Wash \\
\hline 5 & Good fastness & Shade unaltered \\
4 & Fair fastness & Very slight loss or alteration \\
3 & Moderate fastness & Appreciable loss or alteration \\
2 & Slight fastness & Distinct loss or alteration \\
1 & Poor fastness & Great loss or alteration \\
\hline
\end{tabular}


Table-II

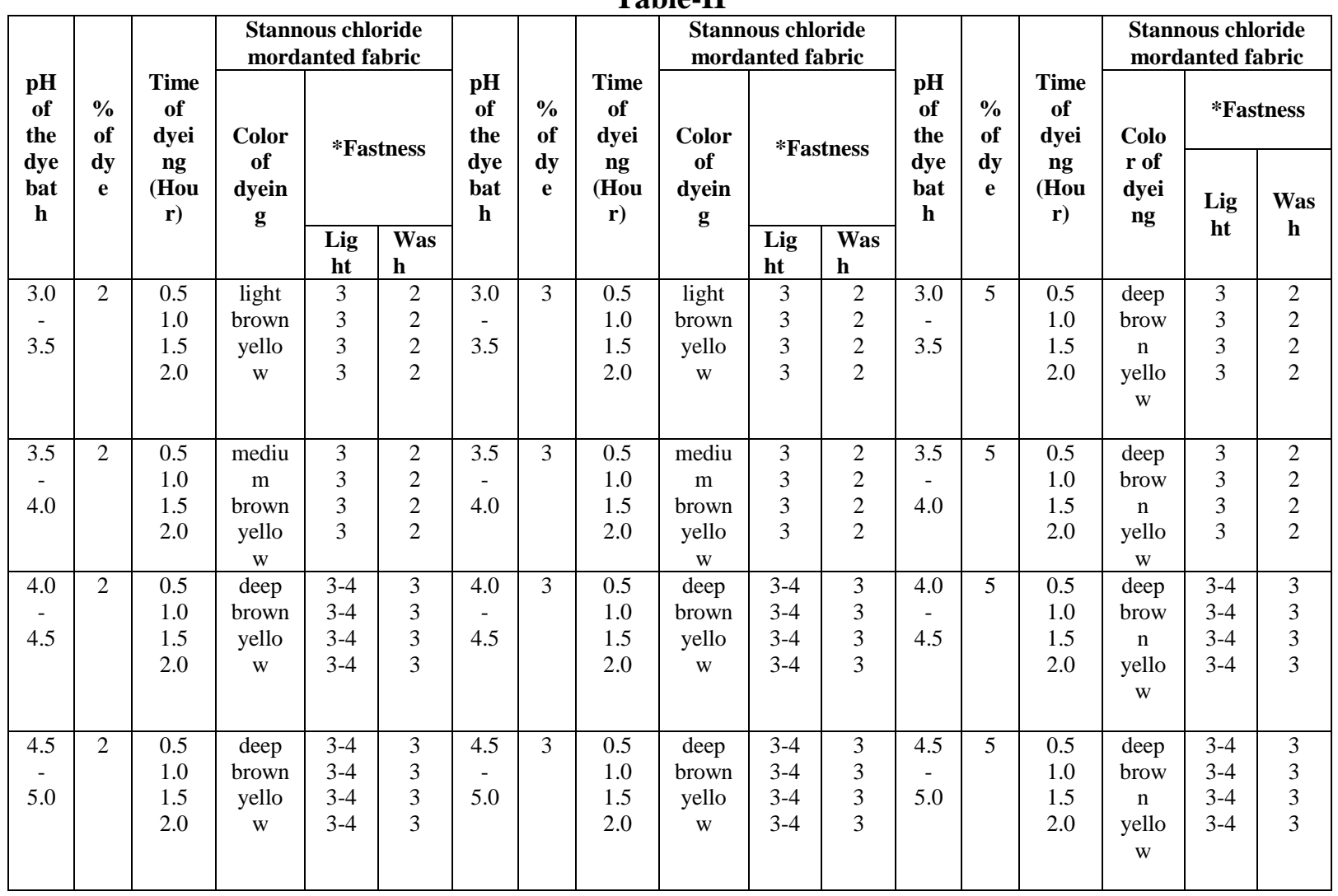

\section{Table-III}

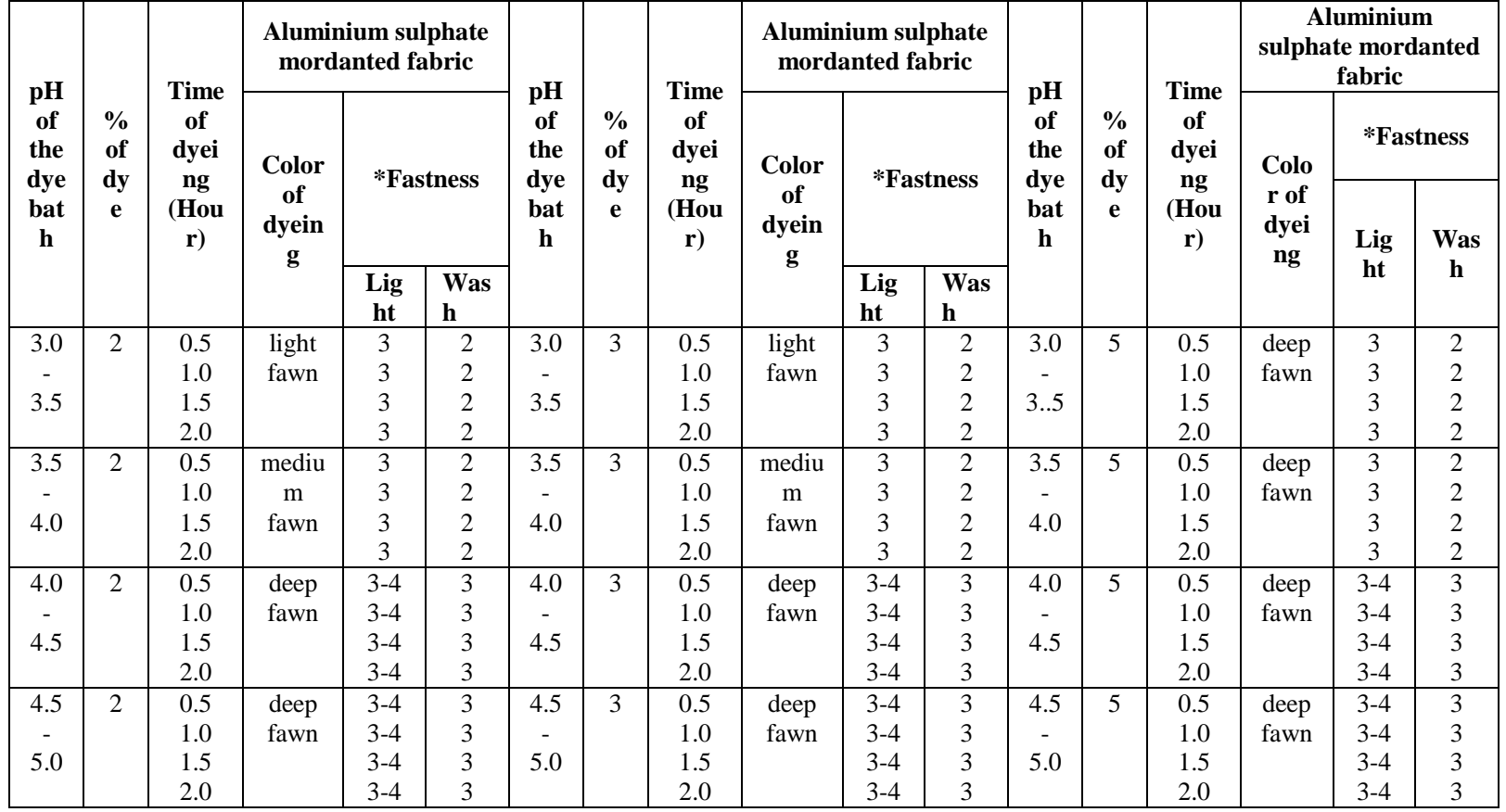

